\title{
Societal targeting in researcher funding: An exploratory approach through dimensions and interactions
}

\author{
Irene Ramos-Vielba ${ }^{1 *}$, Duncan A. Thomas ${ }^{1}$, Kaare Aagaard ${ }^{2}$ \\ ${ }^{1}$ Danish Centre for Studies in Research and Research Policy, Department of Political Science, Aarhus \\ University, Aarhus, Denmark \\ ${ }^{2} R \& D$ Centre for Quality of Education, Profession Policy and Practice, VIA University College, Aarhus, \\ Denmark \\ *Corresponding:iravi@ps.au.dk
}

\begin{abstract}
Shaping public research to enhance its societal contribution has become a key policy concern. Against this background, how research funding may stimulate the societal orientation of scientific research has been underexplored. This paper proposes a two-fold exploratory approach both to characterize and observe societal targeting in individual researcher funding. First, stemming from literature, policy and practices, we select four key societal targeting dimensions: interdisciplinarity, transdisciplinarity, prioritized research problems and user-oriented outputs. All these targeting dimensions of funding can potentially shape both research networks and practices towards societal goals. These dimensions may be identified in context through ex ante specifications of funding instruments, in rules and conditions for funding provision to researchers. Second, we also consider potential interactions of funding instruments, since researchers may engage with various instruments simultaneously when conducting their research. Therefore, each researcher funding configuration at a moment in time may generate bespoke shaping of research, depending on the societal targeting dimensions present and whether funding is co-used to support different research topics and activities within a researcher's portfolio. The combination of the targeting dimensions and their potential interactions would allow for empirical exploration at different scales and in diverse settings. They expand our understanding of funding use dynamics that might shape research. This systematic perspective on funding instrument characteristics and their configurational possibilities will be relevant to assess the role of funding in research evaluation. We conclude with both policy implications of this exploratory societal targeting approach to funding and suggestions to expand it in further research.
\end{abstract}

\section{Keywords}

Societal targeting, Research funding, Researchers, Exploratory approach, Funding instruments, Funding configurations

\section{Introduction}

Since the 1990s, there has been growing emphasis by policymakers on how to accelerate and augment the societal contribution of public research. A strong belief in the importance of universities as engines of research-driven growth and innovation (Pavitt 2001; Geuna 
and Muscio 2009; Grimaldi et al. 2011) has progressively led to a policy push for scientific research to have greater societal relevance. There has also been increased articulation of the policy needs and goals for research to be shaped around, in order to help tackle grand societal challenges (Boon and Edler 2018; Kuhlmann and Rip 2018). Additionally, there has been broader policy interest to promote not only economic but also social, cultural and environmental returns from publicly-funded research. Relatedly, research funding has transitioned from mainly internal provision via block institutional allocations to proportionally more project-based grants, competitively awarded by a wide variety of external organisations (Gläser 2019). There are many drivers behind these changing funding conditions. However, they broadly indicate ambitions by policymakers and funders to increase the 'societal targeting' of research. Furthermore, as a consequence of these changing conditions, scientific researchers not only potentially interact with more complicated constellations of funders, but also with various societally-oriented research funding characteristics (Gläser and Serrano Velarde 2018; Aagaard et al. 2021).

We argue these combined developments call for new approaches to explore how research funding may stimulate societal goals. Funding, and the design of research funding instruments in particular, are viewed to have a central role in defining the scope, content and direction of public research (Whitley, Gläser and Engwall 2010; Bloch and Sorensen 2015; Aagaard 2017; Young et al. 2017). A better understanding of how research funding can become targeted towards societal objectives, therefore, is vital. To do this involves both improving understanding of funding instrument characteristics, and considering potential interactions between different instruments researchers may use, given they may hold multiple instruments at once. These are relatively overlooked aspects in existing literature and represent a research gap. If addressed, this provides better understanding of potential ways that research funding may shape research towards societal aims. Such a two-fold approach is also relevant for research evaluation in situations where the role of funding is often assessed. A standardized approach to characterize funding instruments is a precondition to explore systematically the role of funding across the range of instruments and settings that can exist. Complementarily, observing funding dynamics in a researcher funding configuration may contribute to understand better potential interactions between instruments in relation to research shaping.

Focusing on the researcher level, as opposed to looking at funding systems overall, is particularly important for this type of exploration. Researchers are obligatory points of passage for potential change, such as funding shaping research (Laudel and Gläser 2014). Individual researchers generate a knowledge contribution in a field, determine essential elements of the research work process, and ultimately decide how they use research funding. Researchers are also key actors because how they adapt their behaviour to funding will affect the kinds of research networks and practices that may lead to societal goals (Williams 2020). It is, therefore, crucial to anchor examination of research funding at this analytical level.

From this researcher-led perspective, we will develop an approach built upon two consecutive funding units: funding instruments and funding configurations. First, a funding instrument is a standardised unit that is common across various funding contexts and possibilities in global science. Instruments are the most basic resource unit provided to a researcher by any funder (e.g. a specific project grant, a particular fellowship or budget for a time-limited research centre). We assume funding instruments may become societally targeted in various ways by funders, to orient the direction of funded research towards societal goals. Second, single funding instruments may interact when a researcher has 
various instruments simultaneously. Hence, we will also employ a funding configuration concept as a second funding unit. This unit frames a snapshot of the assorted, concurrent funding instruments and associated funding characteristics a researcher holds. The main aim is that by focusing on societal targeting in researcher funding, novel analytical possibilities can be developed that account for the increasingly differentiated funding realities that researchers face. The two elements of our approach to societal targeting also have implications for research evaluation. This is due to highlighting the need to consider both systematic characterization dimensions and potential interaction effects between different funding instruments held by the same researcher during any evaluation. Throughout, however, we must also recall that any influence to shape research is likely to be highly mediated, multifaceted and multidirectional. Therefore, by focusing on societal targeting of funding, we are not assuming a linear, causal relationship between funding and research.

Based on these premises, this paper presents an exploratory approach to both characterize and observe societal targeting of research funding. The paper is structured as follows: First, section 2 reviews literature on changing funding conditions as a core foundation for our work. Next, our approach to societal targeting in research funding is outlined in two steps. This first presents the selected key societal targeting dimensions of funding instruments (section 3), and then defines researcher funding configurations considering possible funding co-use interactions (section 4). Finally, section 5 reflects on the contribution of this approach to research funding studies and concludes with suggestions to take the approach forward in future research.

\section{Literature review}

This review will first discuss general trends at the system level of research policy, highlighting increasing emphasis on funding to support societal goals. Next, the review will show limited knowledge is available about how funders specifically seek to stimulate a societal orientation in research, through the funding instruments they provide to researchers. Finally, we will review emerging research that focuses on the need to understand better how funding instruments work at researcher level.

\subsection{Increasing funding system emphasis on societal goals}

The funding system, and its associated research policy and funding policy trends, has increasingly been recognised as a major factor in the governance of science in the overall public research system (Braun 2003; Edqvist 2003; Sörlin 2007; Whitley, Gläser and Engwall 2010; Bloch and Sorensen 2015; Aagaard 2017; Young et al. 2017; Lepori and Reale 2019). However, funding at this level has been undergoing dramatic changes in recent decades (Lepori and Reale 2019). Most importantly, a critical trend across many countries has been a substantial increase in the share of funding for researchers coming externally from research councils and other funding organisations while the share from internal, block grant, institutional allocations is decreasing (Bourke and Butler 1999; Langfeldt 2001; Geuna and Martin 2003; Laudel 2006; Heinze 2008; Aagaard 2017). Simultaneously, there has been a steady increase in the number of different project funding instruments available to researchers (Lepori et al. 2007; Franssen and de Rijcke 2019).

There are multiple reasons for these developments. These include New Public Management (NPM) inspired trends, like increased accountability for use of public funding or a strengthened belief in using competition to allocate funding (Nedeva and Boden 2006; Lorenz 2012). Another consideration in the same vein would be a renewed focus that 
supporting excellent research is best done by highly selective funding allocation (Aagaard, Kladakis and Nielsen 2020). However, other parallel developments reflect an apparently growing belief that expectations that research should fulfil societal goals need to be stimulated, and that funding could provide this stimulation, e.g. funding research 'missions'(Boon and Edler 2018; Kuhlmann and Rip 2018). Underpinning these trends is the idea that funding can be used to influence research activities, specifically through appropriate ex ante funding specifications.

Exploring such funding expectations and specifications that aim to enhance the societal orientation of research is not an easy task. To date, there is little systematic insight from previous research about how this should be done. The types of societal contribution that research is expected to deliver, and the mechanisms by which they may be generated, are seemingly subject to shifting demands from society, policymakers and research funders (Audretsch 2014). Such shifting demands are in turn translated into research funding priorities. An example is how, during the past two decades, both policy and scholarly interests have expanded from largely only considering commercialization and application of research findings, to including broader social, cultural, environmental and economic objectives for funded research. Traditionally, utilitarian research policy concerns (Williams 2020) tended to focus on tangible economic effects of research, such as developing profitable applications, securing intellectual property, and creating marketable products to the exclusion of considering other potential societal goals of research (Bornmann 2013). Nevertheless, at the system level, a range of additional funding expectations have also highlighted the possibility of wider uses and benefits of research for society, e.g. for the public sector, in health research, in generating public value, or related to tackling grand societal challenges (van der Meulen and Rip 2000; Mostert et al. 2010; Bozeman and Sarewitz 2011).

\subsection{Limited knowledge about how funders stimulate societal research goals}

Even with this increasing funding system focus on societal goals, and related funder expectations, there is limited knowledge about how the funding instruments that funders provide are actually designed to (attempt to) stimulate societal research goals.

Some steps have been taken in previous research to develop general classifications. These have been based on the differing aims and objectives of particular classes of funding and funding instruments. Overall, this group of studies has mainly explored competitive research funding instruments, addressed at a high level of aggregation, using generic categories. Potì and Reale (2007), for instance, consider different kinds of funding: (i) free projects/grants (blind delegation/no restrictions on research topics); (ii) programmes (incentive delegation/funding for defined policy priorities); and (iii) networks (delegation to a network of research organisations/virtual centres). Lepori et al. (2007: 250) distinguish between different funding types using three similar categories: (i) academic instruments oriented at scientific results/publications/PhDs; (ii) thematic instruments oriented at policy priorities; and (iii) innovation instruments oriented at innovation and economic development in companies. Similarly, Veletanlić and Sá (2020), inspired by Stokes (1997), differentiate between funding instruments aiming to support: (i) pure basic research (Bohr's Quadrant); (ii) pure applied research (Edison's Quadrant); and (iii) use-inspired basic research (Pasteur's Quadrant). Likewise, the OECD (OECD, 2018) and EU have funded studies working with similar categorisations - including the PRIME European network (2004-08) and the EU-sponsored Public Funding of Research (PREF) consortium (Jonkers and Zacharewicz 2016). 
This set of literature serves to confirm that there are indeed different funding instruments and classes of funding that can have broadly diverse aims and objectives by design. However, these approaches do not offer much detail about which funding instrument characteristics can shape funded research towards societal goals. They also do not highlight particular funding specifications used by funders, and do not map which funder expectations systematically underpin the various types of funding employed by funders. Some previous funding studies have examined the specific aims of certain instruments. However, these have typically been instruments with narrow, non-societal aims, e.g. to stimulate breakthrough research (Heinze 2008; Prendergast, Brown and Britton 2008). Studies of which funding instrument characteristics are associated with societally oriented research objectives are missing (Logar 2011; Biegelbauer, Palfinger and Mayer 2020).

Without such knowledge from previous research, we need to begin from first principles. First, it must be assumed that funders may enact their priorities and expectations through potentially multiple different levers, in terms of the funding instrument specifications they develop. Second, it should be assumed that some of these levers may be more or less amenable to the research they fund being able to fulfil specific policy objectives. Third, there is a need to identify and understand which funding instrument characteristics can attempt to steer research towards societal outcomes. Relying on generic funding types and the names of funding instruments will not provide this understanding. Focusing on identifying relevant instrument characteristics and specifications seems a useful way, based on the limits and gaps of previous research, to improve understanding of how funding may shape research towards societal goals.

\subsection{A diversified funding reality at researcher level}

There also seems to be insufficient attention given in previous research to how funding actually manifests at researcher level. This is vital to consider. Transformation of funding landscapes into increasingly multi-actor, multi-level systems, has led to variegated funding actors operating concurrently (e.g. supranational, national, regional, public, private, philanthropic). These varied funders can have many different objectives (Sörlin 2007; Boon and Edler 2018; Gläser and Serrano Velarde 2018; Kuhlmann and Rip 2018; Wagner 2019; Aagaard et al. 2021). The increase in numbers and varieties of funders is acknowledged in literature, but its implications have seemingly been overlooked. Some recent studies have called for a reality check of this new funding situation (Lepori 2011; Gläser and Serrano Velarde 2018; OECD 2018; Gläser 2019; Cocos and Lepori 2020; Aagaard et al. 2021). However, both the inherent diversification of actors potentially attempting to use funding instruments to achieve different goals, and the resulting complexity of funding environments, challenge previous approaches to study research funding. Certain funders are increasingly important in some settings, like charities and supranational funding agencies (Nedeva 2013; Luukkonen 2014). Entirely new funding schemes have emerged in others (Lepori et al. 2007). The overall research funding environment is now markedly diverse, with an expanded variety of funding for researchers. It has therefore become possible for researchers to have more than a single funding instrument at once, which may lead to specific use dynamics around the potential for funding to shape research, as instruments may interact.

Research funding at individual researcher level can then be best understood as a mix of assorted funding instruments. This issue has not yet received sufficient research attention. Instead, single sources of funding are often studied in isolation (e.g. Langfeldt et al. 2015; Neufeld 2016). Some authors have called for more comprehensive studies, 'to 
determine how the various funding sources interact', in these instances, 'as either complements or substitutes, and how this relationship changes with different types of projects' and over researchers' careers (Feldman and Graddy-Reed 2014: 521). However, as much current knowledge is built upon studies of single instruments, there is limited understanding about how different combinations of funding instruments used by a researcher might shape research.

This overall review of funding trends and studies leads us to the two key elements of our approach to research funding. First, it is clear there is a need to identify funding instrument characteristics that might be associated with funder expectations to shape research towards societal goals. Second, there is a need for an approach that accommodates the possibility that an individual researcher may hold more than one funding instrument at a time, with possible interactions between funding instruments. The possibility of such combinatorial effects of funding instruments has recently been considered (Hellström and Jacob 2017; Gläser 2019; Aagaard et al. 2021). However, this is not specifically addressing funding of societal goals of research.

\section{Societal targeting in researcher funding instruments}

The two-fold exploratory approach we propose addresses the above shortcomings in previous literature. It enables both characterization and further observation of societal targeting in researcher funding contexts (Table 1). The characterization examines funding instruments through the lens of their ex ante specifications, focused on a set of dimensions considered as key indicators of societal targeting. Complementarily, observation is based on funding use dynamics, highlighting the potential for interactions between funding instruments within a researcher funding configuration.

Table 1. An exploratory approach to societal targeting in researcher funding

\begin{tabular}{|ll|l|l|l|l|}
\cline { 3 - 6 } \multicolumn{1}{c|}{} & Step & Funding lens & Focus & Unit of analysis \\
\hline \multirow{2}{*}{ Two-fold } & Characterisation & Ex ante specifications & Dimensions & Funding instrument \\
\hline B & Observation & Funding use dynamics & Interactions & Funding configuration \\
\hline
\end{tabular}

\subsection{Ex ante specifications}

To begin our approach, we consider that signals of increased attention towards societal goals of research by policymakers and funders have been translated into identifiable funding instrument characteristics. Funder expectations related to societal goals for funded research may be expressed as tangible, objective funding instrument features. To investigate this systematically, we foreground selected instrument specifications. This assumes that funding policy discourse (Skupien and Rüffin 2020) is translated into funding characteristics specified by funders. Paying regard to these ex ante specifications is a precondition for researchers to obtain this funding (Torka 2018). We will label these characteristics as key societal targeting dimensions of funding instruments.

The funding instrument is taken to be a standardized unit of analysis, expressing funder expectations related to societal goals for research. A funding instrument is the basic unit any funder provides. In this way, the instrument is universal across all types of funding. Even when a funder has programmes or schemes with certain characteristics, these will ultimately be executed as discrete instruments (e.g. project grants) allocated to researchers. Considered in this sense, internal funding is also a funding instrument, e.g., when a university provides funding, under certain conditions, to a researcher from the 
institution's block funding grant. Without including internal funding, we may miss important dynamics where it may be used alongside other instruments (OECD 2018) (OECD, 2018). For instance, this could be to complement external funding or cover for a lack of external funding. Internal funding has typically been considered unconditioned (Potì and Reale 2007). However, it can be societally oriented. For example, internal funding can be specified to create societally-themed, internal, cross-faculty research centres in a university, or there can be small internal research projects on societal issues (Luukkonen and Thomas 2016).

Funding instruments vary in how they detail expectations and orientations. This has been captured for the example of multiple funding instruments that all aim to stimulate breakthrough research, but do so using differing funding specifications (Heinze 2008). Similarly, numerous funding instruments attempt to provide researchers freedom to undertake risky research but using varying descriptions of requirements. They can specify the funded research must be at the frontier (e.g. European Research Council grants) (Nedeva 2013; Luukkonen 2014) or provide money without specifying expectations, as with unconditioned research prize money (Franssen et al. 2018). Similarly, we do not consider societal targeting to be a binary, all-or-nothing characteristic of funding instruments. We instead highlight key societal targeting dimensions aiming to increase the likelihood of funded research contributing to address societal goals, but likely with differences in how these dimensions are understood in specific contexts, and in different research fields.

\subsection{Four key dimensions}

With this first part of the approach, we address funding instruments only from an ex ante perspective. This means looking at conditions and rules of funding instruments to discern key societal targeting dimensions. These dimensions need to be explicit, objective, factual and observable in funding documentation (e.g., for funding programmes, in funding calls, funding guidelines, funding contracts).

Based on observing trends of policy discourse, investigating funder practices and relevant insights in existing literature (e.g. Gläser and Serrano Velarde 2018; Aagaard et al. 2021), we consider two aspects of research enable us to capture key targeting markers that can indicate funding of research towards societal aims. The first of these is research network compositions. Here, we are interested in explicit indications of which knowledge co-producers - either from academia or from other sectors - have been included in the funded research. The second marker is research practices that are being funded. This refers to funding specifications related to topic orientations and/or certain types of research outputs. These markers cannot always be assumed to be associated with direct funding expressions of definite funding policy rationales. They may also not necessarily be obvious simply from the name of a funding instrument. Nevertheless, these two analytical markers allow us to capture likely relevant indications of societal targeting that may shape funded research to facilitate or enhance its societal potential.

Moving into more detail, for research networks, we can differentiate between societal targeting of interdisciplinarity networks, and of transdisciplinarity networks. Both forms of societal targeting seemingly aim to increase the degree and/or affect the type of research collaboration and participation that is being funded. This funding may influence the presence of academics from different disciplines (interdisciplinarity) and/or the involvement of non-academic stakeholders in society (transdisciplinarity), e.g., private companies or non-profit organisations being included into the knowledge co-production 
network of the funded researchers. The apparent logic underpinning both types is that interpersonal research collaboration networks, in some way, can be beneficial for funded research to reach societal goals. Previous research has shown these network forms can lead to knowledge cross-fertilization and further research capacity building among the participating actors (Huang 2014). Involvement of academic and/or non-academics in funded research can, however, vary in practice. Some actors will participate in only a nominal way; others may be integrally involved in making research-related decisions, creating knowledge and publishing together (i.e., in co-decision, co-creation, copublication activities).

Funding specifications concerning research practice dimensions can be considered regarding two key aspects, societal targeting in terms of: pursuit of specified societallyoriented research problems; and specification for research outputs to be in some way useroriented (e.g. policy reports, policy briefings, outreach materials, open datasets, and commercialisation related outputs like patents, marketable products or services). Below we provide further detail about each of these four key dimensions.

\subsubsection{Interdisciplinarity}

The societal aims of funded research may benefit from particular knowledge production collaboration features. For our first dimension, funding instrument specifications may state or imply that theories or methods need to be integrated from more than one discipline in the funded research. A primary underlying reason to foster interdisciplinarity would be that the funded research issue may not be satisfactorily tackled if just one discipline in isolation is mobilized; but instead requires some combination of specialised contribution from diverse disciplines. Thus, integration of multiple areas of research insights and approaches could be considered a desirable feature of the funded scientific knowledge creation process (Lyall et al. 2013).

Likewise, further applications of funded research (e.g. towards technology development or into policy design) could be seen as needing insights from across different disciplines to best facilitate implementation. A requirement for interdisciplinarity may be explicitly included in funding specifications. Interdisciplinarity, as a key societal targeting dimension of funding instruments, whether justified in specifications or not, then relies on an apparent rationale that the funded knowledge contribution to society - particularly, its value and significance for real-world contexts - is likely to be enriched by use of diverse cognitive perspectives and by spanning epistemic boundaries in both science and practice. The expected research undertaken via the funding instrument would be inherently of a collaborative nature from a disciplinary point of view.

\subsubsection{Transdisciplinarity}

Similarly, our second societal targeting dimension relates to funding instrument specifications for inclusion of non-academics into the knowledge production process. The basis for this argument is that increasing complexity of real-world problems requires incorporating epistemologies and methodologies that go beyond simply disciplinary research (Walter et al. 2007). This is a specific understanding of transdisciplinarity, dating back to the 1980s in Europe, putting distinctive emphasis on participation of a wider range of society stakeholders (Klein 2006, 2008). Such inclusive processes can integrate cultural values, practical knowledge and know-how from different types of practitioners (Hansson and Polk 2018). The involvement of non-scientific domains is therefore assumed to facilitate socially robust knowledge (Polk 2014). Additionally, broader insights, tacit 
knowledge and grassroots skills may also contribute to the generation of more effective responses to societal problems and final societal benefits. Knowledge co-creation with stakeholders in society, then, follows a logic of expanding the perspective of approaches throughout the research process to enhance research results.

Funding of this kind exists, for example strategic funding requiring academic researchers to collaborate with non-academics (Feldman and Graddy-Reed 2014). Some indications of this dimension in funding instruments may include ex ante specifications on publicly sharing of research data and, in some occasions, the funded researcher foregoing intellectual property rights or licensing revenues. Another variation on this dimension can be seen in a growing number of funding programmes at national and supranational levels, like the European Union, which call explicitly for wider dissemination and improved utilization of findings by involving firms and other non-academic actors in the research process (Perkmann et al. 2021). Additional transdisciplinarity requirements could include funding of formal or informal tasks by stakeholders, e.g. to provide advice, to add legitimacy to a piece of research, or to contribute insights regarding technical and instrumental solutions based on contextual non-academic knowledge.

Overall, the rationales for such transdisciplinarity specifications are for a redrawing of traditional boundaries between research, stakeholders, and citizens. This is in line with post-normal science (Funtowicz and Ravetz 1993) and of rethinking the societal role of research. Still in this vein, integrating more collective perspectives from local knowledge and non-researcher expertise promotes democratization of public research, when the funded research is expected to be highly inclusive in participative terms.

\subsubsection{Prioritized research problems}

A third key dimension involves looking for specifications of the particular research problems to be addressed within the topic orientation of the funded research. This targeting will then affect the research content, such as its research questions and ultimate goals. It may also have implications for the research approach, methods used, and experimental scope. The rationale for this targeting dimension is that problem-solving research is societally desirable, and that explicitly indicating it in funding specifications may cause it to happen rather than leaving these matters entirely unspecified.

This third societal targeting dimension may then influence both research processes and outputs, aiming to generate knowledge that is sensitive to concrete societal needs, and relevant for certain societal actors (e.g. for an industrial sector, for types of patients). Previous research has highlighted some instruments that seek to increase the orientation of funded research towards pre-defined priority areas (Geuna 2001; Braun 2003; Lepori et al. 2007). Researchers are also known to adjust their research towards the direction of societally targeted funding instruments, in various ways, e.g. in the case of provision of public funding instruments for stem cell research (Kishi 2020). If this dimension can be discerned in funding specifications, the knowledge generated by the funded research, therefore, is likely expected to be suitably applicable in relation to identified problemsolving needs.

\subsubsection{User-oriented outputs}

The fourth key dimension looks for funding specifications on the funded research outputs to have user-orientation. Like in the three other key dimensions, this indicates a particular interest that the research being funded should contribute valuable knowledge to society. 
For this dimension, it is specifically considered the generation of outputs in adaptable forms for different end-users (e.g. local communities, large businesses, national policymakers, broader audiences). This dimension targets that funding leads to research outputs that can be transferred to diverse research beneficiaries for them to appropriate into practice.

Knowledge production to fit potential users may, for instance, be stimulated through openness to include and address external knowledge into research activities (Olmos-Peñuela, Benneworth and Castro-Martínez 2018). Funded researchers may also widen their channels of dissemination to try to produce more transferable, actionable research outputs to end-users. For example, this might include tailoring research findings for different target audiences, translating findings into more accessible/easily understandable terms or into multiple languages, and producing outputs in varied formats, not only academic papers but also knowledge translation products that are easily assimilated by different audiences (Grimshaw et al. 2012). The underlying rationale for this dimension then is that the funded research would be expected to be easy to absorb for users and/or be widely usable in societal settings, public policy contexts or in private spheres.

Table 2 provides an overview of these four key societal targeting dimensions of research funding, the aspects of research activity they target, the knowledge contributions to society that are being implicitly or explicitly targeted, the markers of these targeting in research, and the nature of the expected research that would arise from the funding.

Table 2. Four key societal targeting dimensions in research funding instruments

\begin{tabular}{|c|c|c|c|c|c|}
\hline$\#$ & $\begin{array}{l}\text { Societal targeting } \\
\text { dimensions }\end{array}$ & $\begin{array}{l}\text { Targeted } \\
\text { aspects }\end{array}$ & $\begin{array}{l}\text { Targeted knowledge } \\
\text { contributions to society }\end{array}$ & $\begin{array}{l}\text { Targeting } \\
\text { markers }\end{array}$ & $\begin{array}{l}\text { Expected } \\
\text { research }\end{array}$ \\
\hline $\mathbf{I}$ & Interdisciplinarity & \multirow{3}{*}{$\begin{array}{l}\text { Research } \\
\text { process }\end{array}$} & $\begin{array}{l}\text { Cognitive perspectives } \\
\text { Epistemic complementarity }\end{array}$ & \multirow{2}{*}{$\begin{array}{l}\text { Research } \\
\text { networks } \\
\text { (e.g. } \\
\text { composition, } \\
\text { role, } \\
\text { involvement) } \\
\end{array}$} & $\begin{array}{l}\text { Inherently } \\
\text { collaborative }\end{array}$ \\
\hline $\mathbf{T}$ & Transdisciplinarity & & $\begin{array}{l}\text { Non-academic / tacit knowledge } \\
\text { Co-creation of knowledge }\end{array}$ & & $\begin{array}{l}\text { Inclusively } \\
\text { participative }\end{array}$ \\
\hline $\mathbf{P}$ & $\begin{array}{l}\text { Prioritized } \\
\text { research problems }\end{array}$ & & $\begin{array}{l}\text { Problem-solving / societal needs } \\
\text { Sensitive \& relevant knowledge }\end{array}$ & \multirow{2}{*}{$\begin{array}{l}\text { Research } \\
\text { practices } \\
\text { (e.g. priorities, } \\
\text { approaches, } \\
\text { methods) }\end{array}$} & $\begin{array}{l}\text { Suitably } \\
\text { applicable }\end{array}$ \\
\hline $\mathbf{O}$ & $\begin{array}{l}\text { User-oriented } \\
\text { outputs }\end{array}$ & $\begin{array}{l}\text { Research } \\
\text { output }\end{array}$ & $\begin{array}{l}\text { Practical \& useful knowledge } \\
\text { Benefit \& value to society }\end{array}$ & & Widely usable \\
\hline
\end{tabular}

In practice, any number of the four key dimensions could be seen in an actual funding instrument. For example, an instrument with all four dimensions would be societally targeted to address societal goals through extensive collaboration across academic disciplines, with broad participation of non-academic actors, to tackle a concrete prioritized research problem so as to ensure adequate applicability of the funded research, and would be expected to make funded research outputs usable in diverse contexts.

To complete this characterization of societal targeting at funding instrument level, we also need to consider that the strength of specification may vary for each key dimension. Two funding instruments, even with similar key societal targeting dimensions, may not be identically specified. We can extrapolate from previous research to consider this aspect may be analogous to the degree of delegation from funders to researchers (Braun 2003; Potì and Reale 2007). At the extremes, the dimensions of an instrument could be highly specified by a funder or, conversely, all decisions about research processes and 
outputs may be delegated to the funded researcher. Similarly, requirements may be stipulated broadly or narrowly. For example, narrow funding instrument specification could indicate precise disciplines need to be involved or certain industry sectors or stakeholder types to participate. Alternatively, an instrument may only minimally specify these aspects or only in broad, general terms. Finally, strength of specification may not automatically lead to highly or slightly societally-oriented research; this should be determined empirically.

\section{Societal targeting in researcher funding configurations}

The second part of our approach involves additional considerations that are necessary to observe researcher funding in context (see earlier Table 1). Against a background of more varied funding provision, researchers can use various instruments simultaneously (Aagaard et al. 2021). These funding use dynamics suggest that societal targeting of funding instruments can potentially interact in researcher level funding configurations - with implications for the eventual societal goals of funded research.

\subsection{Funding use dynamics and potential instrument interactions}

The possibility of concurrent funding instruments in researcher funding implies that these instruments might interact in different ways (Shapira and Wang 2010; Hellström and Jacob 2017; Gläser and Serrano Velarde 2018; OECD 2018; Aagaard et al. 2021). Interaction is most likely in instances of co-funding of the same research, when a researcher co-uses funding instruments to pursue connected lines of research. Co-funding has already been observed in certain research fields such as global nanotechnology (Wang and Shapira 2011). This has mainly been noticed in cases of collaborative research, like researchers multi-authoring a paper. However, it has been also proposed that individual researchers may co-fund their research and that this may lead to difficulties or potential friction, depending upon how compatible or associable the co-used instruments are (Hellström and Jacob 2017).

When considering use dynamics and possible instrument interactions with a researcher funding, it is essential to study the researcher's topic portfolios (Luukkonen and Thomas 2016). In cases where a researcher's portfolio involves interdependent, overlapping or closely related research topics this might lead to interactions between their funding instruments. Such interactions could manifest at any point during the development of scientific work, in either research processes or outputs. Conversely, if a researcher's portfolio consists of largely detached, independent research topics this would make it less likely to use funding instruments in a connected way, where they interact, although they would still coexist. The interconnectedness and interdependency of the research topics addressed by a researcher can, therefore, become a mediating factor in possible funding instrument interactions.

In exploring why instrument-to-instrument interaction might occur, we need to recall that researchers often do not just carry out discrete, short-term, disconnected research tasks over time. Instead, they can pursue long-term, overarching research themes within a broad agenda (Luukkonen and Thomas 2016). In formal terms, a researcher has a cognitive career. Rather than doing disjointed research work, this career involves them undertaking 'thematically connected problem-solving processes in which findings from earlier projects serve as input in later projects', and this can involve 'one or several distinct "research trails" at the same time' (Laudel and Bielick 2019: 3). To do this, a researcher may need to co-use their funding instruments, especially if the resources of one instrument 
alone are insufficient to pursue a larger goal. Any co-use is therefore likely highly context dependent. Some researchers may be able to continue pursuing their specific research agendas under conditions of scarce funding (Horta and Santos 2020). Others may co-use multiple funding instruments in a highly connected, interdependent fashion (Thomas et al., 2020) or may use their funding independently.

To understand better what instrument interactions might mean, this may occur in simple ways, e.g., if concurrent funding instruments involve the same academic actors, non-academic stakeholders, or overlapping research problems and user-oriented outputs. Overall co-use and interaction dynamics are likely to be nuanced and complicated, requiring empirical exploration to understand. Regardless, it seems beneficial to include the possibility of such interactions in our approach to societal targeting in researcher funding configurations.

\subsection{Researcher funding configurations}

To observe the researcher funding context, our selected unit of analysis is a funding configuration. This is defined as a snapshot of the concurrent assortment of funding instruments a researcher holds at any moment in time, including both internal and external funding instruments. A configuration provides a larger frame of analysis to observe in what ways these instruments may differ from each other and may interact in influencing shaping of research. Within a configuration, instruments - either from the same funder or from separate funders - may have different societal targeting.

For our exploratory approach, the configuration analysis would register each unique researcher funding and its societal targeting mix. For illustration, we present a hypothetical societally targeted configuration (Figure 1). This shows a changing sequence of instruments held over time by this example researcher. Each instrument shown (block) has certain characteristics, like duration (horizontal axis) and resource level (vertical axis). Additionally, each instrument can have any of the four key societal targeting dimensions (from Table 2). In this example, the researcher has a configuration (dotted box) comprised of three instruments: one with four dimensions (I, T, P and $\mathrm{O}$ ); another with three dimensions (I, $\mathrm{T}$ and $\mathrm{O}$ ); and one with two dimensions ( $\mathrm{P}$ and $\mathrm{O})$.

Figure 1. An example researcher's societally-targeted funding configuration

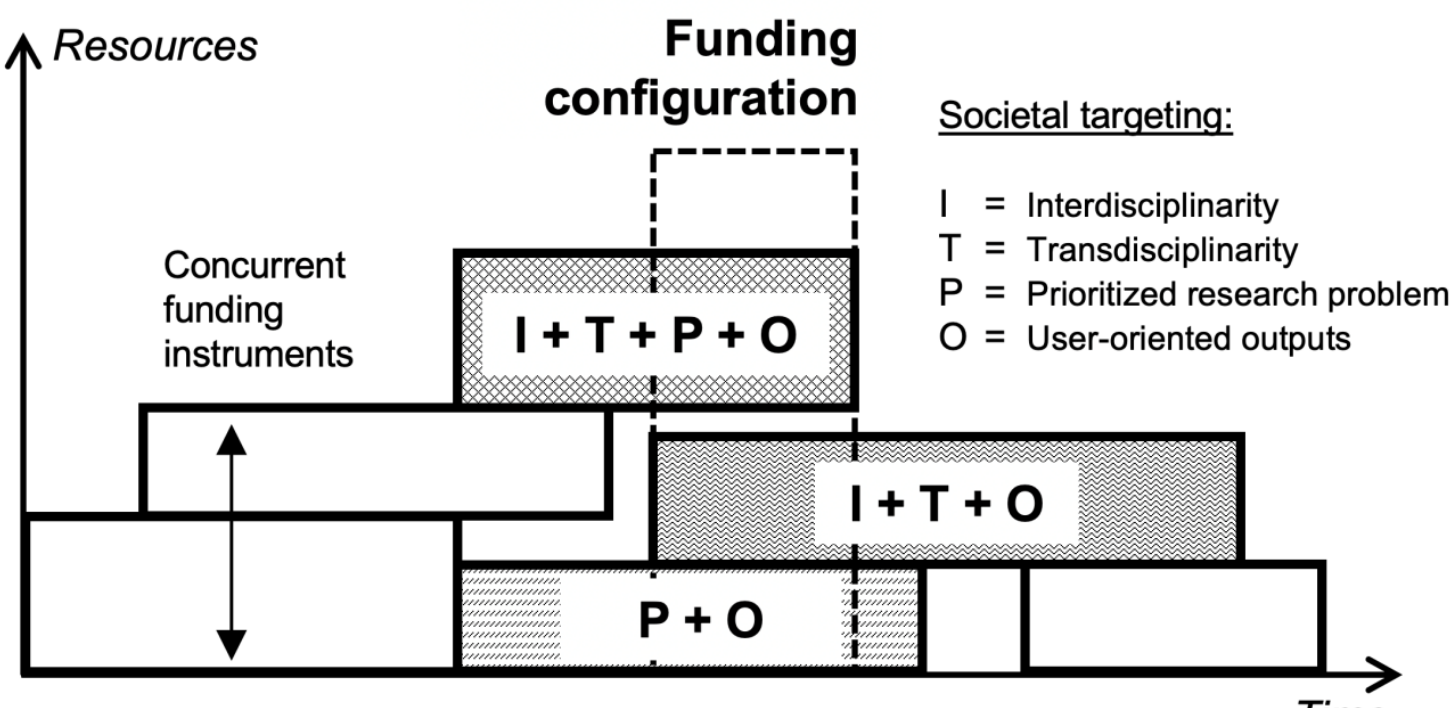

Time 
By comprehensively observing the characteristics of the configuration of funding instruments a researcher holds, the approach does not overlook the possibility of influences from various instruments and their associated societal targeting dimensions. Within this full set of instruments, each societal targeting dimension may have a potential role in shaping the funded research - and in interacting with other instruments in this shaping. Additionally, we can consider a researcher longer-term funding trajectory, by exploring the sequence of their varying funding configurations over time. This approach, then, allows funding instruments to be addressed comprehensively and systematically, in connection to potential shaping of research. From this perspective, funding configuration sequences can be considering as ultimately aggregating more than the sum of their parts in terms of shaping research towards societal goals.

Finally, both units of analysis, funding instruments and funding configurations, with their associated dimensions and interactions, can be combined into an overall illustration of our exploratory approach (Figure 2).

Figure 2. Schematic of an exploratory approach to societal targeting in researcher funding

Funding configuration

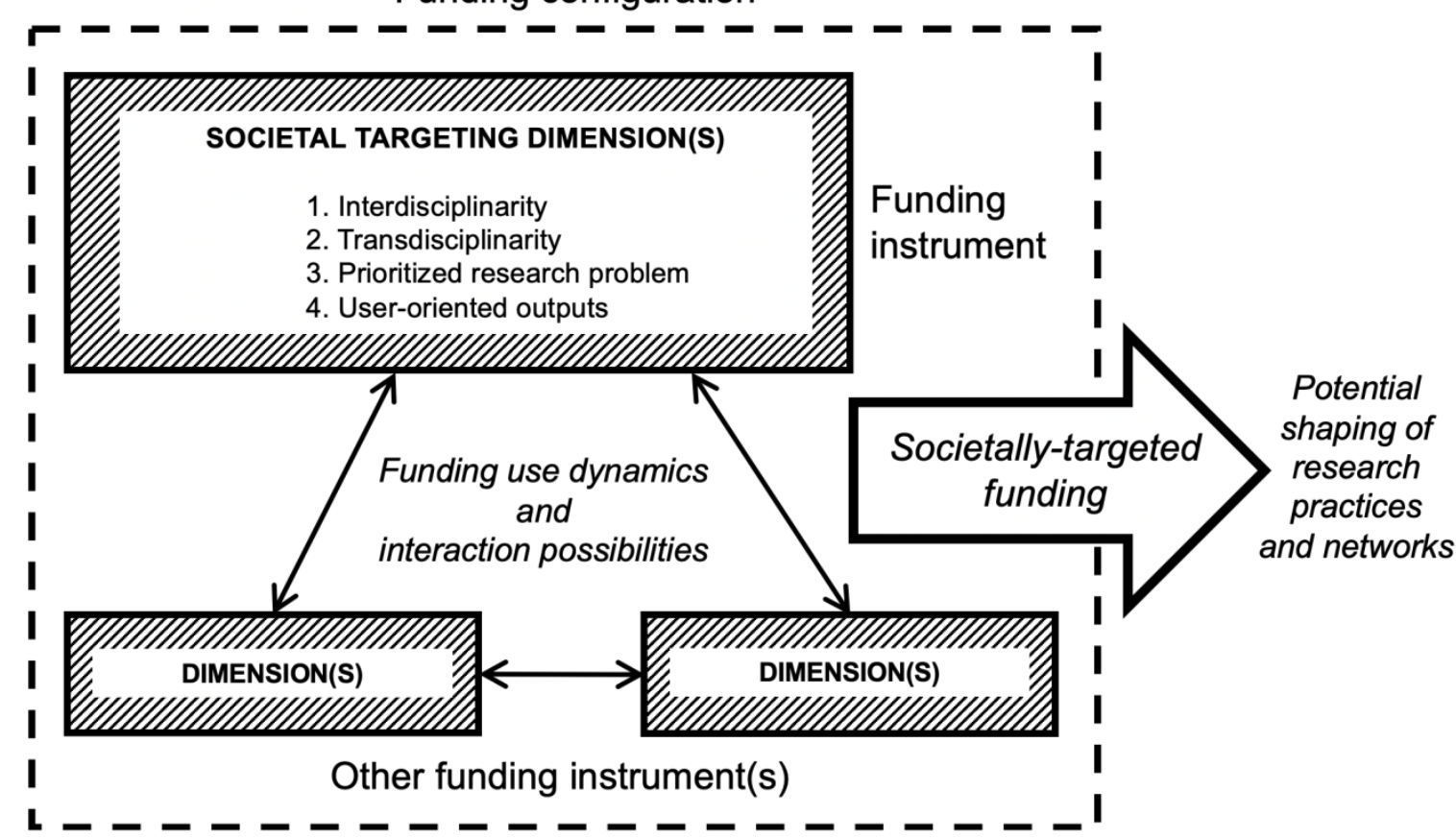

\section{Discussion and conclusions}

In this paper we have provided an approach to explore societal targeting in both funding instruments and funding configurations at individual researcher level. Insights from previous funding studies and funding practices inspire this approach, with which we hope to move beyond intangible notions in policy and funder discourses around societal expectations (e.g. goals, challenges or missions). Instead, the focus is on a systematic set of societal targeting dimensions that can be present in funding instruments and, therefore, on funding use dynamics and potential interactions within researcher funding configurations. We have also rooted the characterization and observability of societal targeting in funding policy trends related to what is considered as societal aims of funded research, how funders attempt to shape research, and the diversified funding context that can be manifested at researcher level. 
We expect there are benefits to this articulation of societal targeting, which facilitates its study at the level of funding held by individual researchers. A primary benefit is that the use of two standardized units of analysis - funding instruments and funding configurations - could make possible comparison across various settings. The configuration of interacting instruments introduces an important, yet largely unexplored, analytical layer potentially mediating between the societal targeting of specific funding instruments, and influences that possibly shape research. The approach could also facilitate mapping of research networks and practices as societal targeting markers of attempts to translate expectations from policy, funding and society into funded research that may help achieve societal goals over time.

The effective societal targeting to which a researcher is subjected, specifically associated with their funding configuration at any one time, emerges from this exploratory approach as complicated. Besides the multiple individual, organizational and contextual influences that can affect a researcher's research networks and practices (D'Este et al. 2018), we must add interaction-related funding use dynamics. In such settings, researchers' research topic trails may moderate funding interactions, particularly when taking a longitudinal perspective. Two main reflections derived from this approach are then that, first, societal targeting funding dynamics at individual researcher level are a worthwhile subject of study. Second, possible shaping of research through societal targeting of funding is likely not amenable to a linear model, where characteristics of funding inputs are directly associated with the funded research practices and networks. Rather, a focus on combinatorial funding targeting of research processes and outputs suggests continuous, open and multi-directional possibilities of shaping research towards societal goals.

Acknowledging that contextual factors and other mediating influences can affect societally-oriented research, by identifying an observable scheme of key dimensions of societal targeting, we can move towards operationalization. These key dimensions could be operationalized to study a wide variety of researchers and research settings systematically. In the application of this exploratory approach, suitable methods may include survey-based characterization of funding instruments and observing configurations at scale. At smaller scale, interviews could be used to gain more nuance, and higher resolution about funding instrument specifications, details of a researcher configuration, use dynamics and instrument interactions (Thomas, Ramos-Vielba and Aagaard 2020). Desk-based research on funding instrument specifications could also characterize key societal targeting dimensions. Additionally, for comprehensive studies incorporating the proposed two-fold approach, interviews with both researchers and funders are also likely to be valuable to provide different perspectives. Particularly when the underlying rationales of funding requirements are not codified or fully expressed, and when specification strength is difficult to determine, it may be necessary to examine how researchers and funders understand funding conditions and expectations in practice. Complementarily, for a longitudinal perspective, individual research trails based on bibliometric analyses could identify researchers' topics over time, and be combined with study of funding use, instrument interactions and shaping influences. Lastly, mixed methods could also help to connect societal targeting of funding with research collaborative networks and research practices, given the higher resolution of funding characterization and observation that this exploratory approach may provide.

The selected key dimensions capture how societal targeting is currently understood in contemporary global science. However, what is expected from funded research whether it being collaborative, participative, applicable and usable - may be understood 
differently in different contexts and fields. Other targeting practices, rationales and considerations might later displace or replace these four key dimensions, as policymakers, funders, researchers and society rethink notions around the value of research and the imperatives of their research funding. By adding further dimensions, it should be possible to study, for instance, changing notions about what society desires or needs from funded research, what societal expectations funders and researchers believe are achievable in various contexts, and through which instrumentalities such research is expected to appear.

Addressing such issues may produce valuable insights for policymakers, research funders, research evaluators and scholars, in understanding societal contributions of public science - and the role of funding associated with them. For these actors, there could be benefits to understand funding instruments as operating in configured, potentially interacting contexts at researcher level. Synergies or tensions between funders providing the same researcher(s) with instruments may then become (more) apparent through this view. This could lead to advances in design, provision and monitoring of funding, informed by an appropriate framing of researchers' real-world funding contexts. Similarly, evaluation of research results often informs research management and research policy. In this regard, performance-based assessment of researchers and of their use of previous funding is commonly used to decide upon future funding allocations, under the assumption that funding based on such evaluations will yield greater returns (Geuna and Martin 2003). Simultaneously, different impact evaluation methods have increasingly integrated both scientific and societal value of research indicators, involving construction of a variety of societal value concepts (Smit and Hessels 2021). However, understanding the targeting features of the funding researchers received as a baseline for such evaluations, and considering dynamics of how differently targeted funding has been (co-)used at individual level, may draw further conclusions about researcher performance in connection with the societal orientation of research. The proposed perspective in this paper could then contribute complementary insights regarding societal targeting of funding and its potential shaping of research for both theoretical and practical areas of research evaluation and evaluation-based funding.

There are also areas for further development of this approach. For instance, there is a need for deeper treatment of time and possible path dependency in funding dynamics. We have framed a snapshot of funding at individual researcher level, with the configuration notion. More advanced understanding of funding dynamics may necessitate moving beyond snapshots to explore funding sequences. Then we may find that previous funding instruments a researcher held are interconnected with the current ones. Likewise, a researcher current funding configuration may predetermine their future funding in ways that could be interesting to study. Further research could, therefore, focus on, for instance, how researchers learn with regard to funding characteristics (c.f. Hellström and Hellström 2020). For example, they may develop specific strategies to acquire funding or attempt to shape funding provision to suit their needs.

Finally, agency may be further incorporated into this approach. Research could then explore to what extent researchers do or do not change their research, in response to societal targeting (Laudel 2006). These would be a researcher response component to a broader approach to societal targeting funding dynamics. There is also a need to consider the funder perspective. In particular, the degree to which funders choose to enforce societal targeting dimensions could be included in a future approach. How and when such enforcement is implemented could also vary, even for similarly societally targeted funding instruments. Moreover, given we understand interaction between instrument characteristics 
is possible in configurations, researchers may then face overlapping targeting and enforcement possibilities. Overall, these further research areas could help later to expand this exploratory approach to societal targeting in researcher funding instruments and configurations to incorporate additional details, and to address even more complicated dynamics.

\section{References}

Aagaard, K. (2017), 'The Evolution of a National Research Funding System: Transformative Change through Layering and Displacement', Minerva, 55, 279-97.

Aagaard, K., Kladakis, A., and Nielsen, M. W. (2020), 'Concentration or Dispersal of Research Funding?', Quantitative Science Studies, 1 (1), 117-49.

Aagaard, K., Mongeon, P., Ramos-Vielba, I., and Thomas, D. A. (2021), 'Getting to the Bottom of Research Funding: Acknowledging the Complexity of Funding Dynamics.', PLOS ONE.

Audretsch, D. B. (2014), 'From the Entrepreneurial University to the University for the Entrepreneurial Society', The Journal of Technology Transfer, 39 (3), 313-21.

Biegelbauer, P., Palfinger, T., and Mayer, S. (2020), 'How to Select the Best: Selection Procedures of Innovation Agencies', Research Evaluation, 29 (3), 289-99.

Bloch, C. and Sorensen, M. P. (2015), 'The Size of Research Funding: Trends and Implications', Science and Public Policy, 42 (1), 30-43.

Boon, W. and Edler, J. (2018), 'Demand, Challenges, and Innovation. Making Sense of New Trends in Innovation Policy', Science and Public Policy, 45 (4), 435-47.

Bornmann, L. (2013), 'What Is Societal Impact of Research and How Can It Be Assessed? A Literature Survey', Journal of the American Society for Information Science and Technology, 64 (2), 217-33.

Bourke, P. and Butler, L. (1999), 'The Efficacy of Different Modes of Funding Research: Perspectives from Australian Data on the Biological Sciences', Research Policy, 28 (5), 489-99.

Bozeman, B. and Sarewitz, D. (2011), 'Public Value Mapping and Science Policy Evaluation', Minerva, 49 (1), 1-23.

Braun, D. (2003), 'Lasting Tensions in Research Policy-Making - a Delegation Problem', Science and Public Policy, 30 (5), 309-21.

Cocos, M. and Lepori, B. (2020), 'What We Know About Research Policy Mix', Science and Public Policy, 47 (2), 235-45.

D'Este, P., Ramos-Vielba, I., Woolley, R., and Amara, N. (2018), 'How Do Researchers Generate Scientific and Societal Impacts? Toward an Analytical and Operational Framework', Science and Public Policy, 45 (6), 752-63.

Edqvist, O. (2003), 'Layered Science and Science Policies', Minerva, 41 (3), 207-21.

Feldman, M. P. and Graddy-Reed, A. (2014), 'Accelerating Commercialization: A New Model of Strategic Foundation Funding', Journal of Technology Transfer, 39 (4), 503-23.

Franssen, T. and de Rijcke, S. (2019), 'The Rise of Project Funding and Its Effects on the Social Structure of Academia', in Fabian Cannizo and Nick Osbaldiston (eds.), The Social Structures of Global Academia; Oxon \& New York: Routledge Advances in Sociology.

Franssen, T., Scholten, W., Hessels, L. K., and de Rijcke, S. (2018), 'The Drawbacks of Project Funding for Epistemic Innovation: Comparing Institutional Affordances and Constraints of Different Types of Research Funding', Minerva, 56 (1), 11-33.

Funtowicz, S. O. and Ravetz, J. R. (1993), 'Science for the Post-Normal Age', Futures, 25 (7), 739-55. 
Geuna, A. (2001), 'The Changing Rationale for European University Research Funding: Are There Negative Unintended Consequences?', Journal of Economic Issues, 35 (3), 607-32.

Geuna, A. and Martin, B. R. (2003), 'University Research Evaluation and Funding: An International Comparison', Minerva, 41 (4), 277-304.

Geuna, A. and Muscio, A. (2009), 'The Governance of University Knowledge Transfer: A Critical Review of the Literature', Minerva, 47 (1), 93-114.

Gläser, J. (2019), 'How Can Governance Change Research Content? Linking Science Policy Studies to the Sociology of Science', in Dagmar Simon, Stefan Kuhlmann, Julia Stamm, and Weert Canzler (eds.), Handbook on Science and Public Policy; Cheltenham, UK: Edward Elgar Publishing, 419-47.

Gläser, J. and Serrano Velarde, K. (2018), 'Changing Funding Arrangements and the Production of Scientific Knowledge: Introduction to the Special Issue', Minerva, 56 (1), 1-10.

Grimaldi, R., Kenney, M., Siegel, D. S., and Wright, M. (2011), '30 Years after BayhDole: Reassessing Academic Entrepreneurship', Research Policy, 40 (8), 1045-57.

Grimshaw, J. M., Eccles, M. P., Lavis, J. N., Hill, S. J., and Squires, J. E. (2012), 'Knowledge Translation of Research Findings', Implementation Science, 7 (1), 1-17.

Hansson, S. and Polk, M. (2018), 'Assessing the Impact of Transdisciplinary Research: The Usefulness of Relevance, Credibility, and Legitimacy for Understanding the Link between Process and Impact', Research Evaluation, 27 (2), 132-44.

Heinze, T. (2008), 'How to Sponsor Ground-Breaking Research: A Comparison of Funding Schemes', Science and Public Policy, 35 (5), 302-18.

Hellström, T. and Jacob, M. (2017), 'Policy Instrument Affordances: A Framework for Analysis', Policy Studies, 38 (6), 604-21.

Hellström, T. and Hellström, C. (2020), 'Cross-Sectoral Mobility Funding and the Challenge of Immersion: The Case of Ssh', Minerva, 58 (3), 389-407.

Horta, H. and Santos, J. M. (2020), 'The Multidimensional Research Agendas InventoryRevised (Mdrai-R): Factors Shaping Researchers' Research Agendas in All Fields of Knowledge', Quantitative Science Studies, 1 (1), 60-93.

Huang, J. S. (2014), 'Building Research Collaboration Networks--an Interpersonal Perspective for Research Capacity Building', Journal of Research Administration, 45 (2), 89-112.

Jonkers, K. and Zacharewicz, T. (2016), 'Research Performance Based Funding Systems: A Comparative Assessment', Publications Office of the European Union, Luxembourg.

Kishi, N. (2020), 'How Does Policy Focus Influence Scientific Research?', Science and Public Policy, 47 (1), 114-24.

Klein, J. T. (2006), 'Afterword: The Emergent Literature on Interdisciplinary and Transdisciplinary Research Evaluation', Research Evaluation, 15 (1), 75-80.

Klein, J. T. (2008), 'Evaluation of Interdisciplinary and Transdisciplinary Research: A Literature Review', American Journal of Preventive Medicine, 35 (2), S116-S23.

Kuhlmann, S. and Rip, A. (2018), 'Next-Generation Innovation Policy and Grand Challenges', Science and Public Policy, 45 (4), 448-54.

Langfeldt, L. (2001), 'The Decision-Making Constraints and Processes of Grant Peer Review, and Their Effects on the Review Outcome', Social Studies of Science, 31 (6), 820-41.

Langfeldt, L., Benner, M., Sivertsen, G., Kristiansen, E. H., Aksnes, D. W., Borlaug, S. B., Hansen, H. F., Kallerud, E., and Pelkonen, A. (2015), 'Excellence and Growth Dynamics: A Comparative Study of the Matthew Effect', Science and Public Policy, 42 (5), 661-75. 
Laudel, G. (2006), 'The Art of Getting Funded: How Scientists Adapt to Their Funding Conditions', Science and Public Policy, 33 (7), 489-504.

Laudel, G. and Gläser, J. (2014), 'Beyond Breakthrough Research: Epistemic Properties of Research and Their Consequences for Research Funding', Research Policy, 43 (7), 1204-16.

Laudel, G. and Bielick, J. (2019), 'How Do Field-Specific Research Practices Affect Mobility Decisions of Early Career Researchers?', Research Policy, 48 (9), 103800.

Lepori, B. (2011), 'Coordination Modes in Public Funding Systems', Research Policy, 40, 355-67.

Lepori, B. and Reale, E. (2019), 'The Changing Governance of Research Systems. Agencification and Organizational Differentiation in Research Funding Organizations', in Dagmar Simon, Stefan Kuhlmann, Julia Stamm, and Weert Canzler (eds.), Handbook on Science and Public Policy: Edward Elgar Publishing.

Lepori, B., van den Besselaar, P., Dinges, M., van der Meulen, B., Poti, B., Reale, E., Slipersaeter, S., and Theves, J. (2007), 'Indicators for Comparative Analysis of Public Project Funding: Concepts, Implementation and Evaluation', Research Evaluation, 16 (4), 243-55.

Logar, N. (2011), 'Scholarly Science Policy Models and Real Policy, Rsd for Scisip in Us Mission Agencies', Policy Sciences, 44 (3), 249.

Lorenz, C. (2012), 'If You're So Smart, Why Are You under Surveillance? Universities, Neoliberalism, and New Public Management', Critical inquiry, 38 (3), 599-629.

Luukkonen, T. (2014), 'The European Research Council and the European Research Funding Landscape', Science and Public Policy, 41 (1), 29-43.

Luukkonen, T. and Thomas, D. A. (2016), 'The 'Negotiated Space'of University Researchers' Pursuit of a Research Agenda', Minerva, 54 (1), 99-127.

Lyall, C., Bruce, A., Marsden, W., and Meagher, L. (2013), 'The Role of Funding Agencies in Creating Interdisciplinary Knowledge', Science and Public Policy, 40 (1), 62-71.

Mostert, S. P., Ellenbroek, S. P., Meijer, I., Van Ark, G., and Klasen, E. C. (2010), 'Societal Output and Use of Research Performed by Health Research Groups', Health Research Policy and Systems, 8 (1), 1-10.

Nedeva, M. (2013), 'Between the Global and the National: Organising European Science', Research Policy, 42 (1), 220-30.

Nedeva, M. and Boden, R. (2006), 'Changing Science: The Advent of Neo-Liberalism', Prometheus, 24 (3), 269-81.

Neufeld, J. (2016), 'Determining Effects of Individual Research Grants on Publication Output and Impact: The Case of the Emmy Noether Programme (German Research Foundation)', Research Evaluation, 25 (1), 50-61.

OECD (2018), 'Effective Operation of Competitive Research Funding Systems', OECD Science, Technology and Industry Policy Papers, 57; Paris: OECD Publishing.

Olmos-Peñuela, J., Benneworth, P. S., and Castro-Martínez, E. (2018), 'Does Usable Research Face Higher Obstacles within the Academy?', CHEPS Working Paper Series, 5; Twente: Center for Higher Education Policy Studies.

Pavitt, K. (2001), 'Public Policies to Support Basic Research: What Can the Rest of the World Learn from Us Theory and Practice?(and What They Should Not Learn)', Industrial and Corporate Change, 10 (3), 761-79.

Perkmann, M., Salandra, R., Tartari, V., McKelvey, M., and Hughes, A. (2021), 'Academic Engagement: A Review of the Literature 2011-2019', Research Policy, 50 (1).

Polk, M. (2014), 'Achieving the Promise of Transdisciplinarity: A Critical Exploration of the Relationship between Transdisciplinary Research and Societal Problem Solving', Sustainability Science, 9 (4), 439-51. 
Potì, B. and Reale, E. (2007), 'Changing Allocation Models for Public Research Funding: An Empirical Exploration Based on Project Funding Data', Science and Public Policy, 34 (6), 417-30.

Prendergast, P. J., Brown, S. H., and Britton, J. R. (2008), 'Research Programmes That Promote Novel, Ambitious, Unconventional and High-Risk Research: An Analysis', Industry and Higher Education, 22 (4), 215-21.

Shapira, P. and Wang, J. (2010), 'Follow the Money', Nature, 468 (7324), 627-28.

Skupien, S. and Rüffin, N. (2020), 'The Geography of Research Funding: Semantics and Beyond', Journal of Studies in International Education, 24 (1), 24-38.

Smit, J. P. and Hessels, L. K. (2021), 'The Production of Scientific and Societal Value in Research Evaluation: A Review of Societal Impact Assessment Methods', Research Evaluation.

Sörlin, S. (2007), 'Funding Diversity: Performance-Based Funding Regimes as Drivers of Differentiation in Higher Education Systems', Higher Education Policy, 20 (4), 41340.

Stokes, D. E. (1997), Pasteur's Quadrant: Basic Science and Technological Innovation; Washington: Brookings Institution Press.

Thomas, D. A., Ramos-Vielba, I., and Aagaard, K. (2020), 'Tracing Researcher 'Funding Configurations': Some Initial Approaches and Challenges', SocArXiv, 1-33. $<$ https://osf.io/preprints/socarxiv/d4tr8/>.

Torka, M. (2018), 'Projectification of Doctoral Training? How Research Fields Respond to a New Funding Regime', Minerva, 56 (1), 59-83.

van der Meulen, B. and Rip, A. (2000), 'Evaluation of Societal Quality of Public Sector Research in the Netherlands', Research Evaluation, 9 (1), 11-25.

Veletanlić, E. and Sá, C. (2020), 'Implementing the Innovation Agenda: A Study of Change at a Research Funding Agency', Minerva, 1-23.

Wagner, C. S. (2019), 'Global Science for Global Challenges', in Dagmar Simon, Stefan Kuhlmann, Julia Stamm, and Weert Canzler (eds.), Handbook on Science and Public Policy; Cheltenham, UK: Edward Elgar Publishing Limited, 92-103.

Walter, A. I., Helgenberger, S., Wiek, A., and Scholz, R. W. (2007), 'Measuring Societal Effects of Transdisciplinary Research Projects: Design and Application of an Evaluation Method', Evaluation and Program Planning, 30 (4), 325-38.

Wang, J. and Shapira, P. (2011), 'Funding Acknowledgement Analysis: An Enhanced Tool to Investigate Research Sponsorship Impacts: The Case of Nanotechnology', Scientometrics, 87 (3), 563-86.

Whitley, R., Gläser, J., and Engwall, L. (2010), Reconfiguring Knowledge Production: Changing Authority Relationships in the Sciences and Their Consequences for Intellectual Innovation; Oxford: Oxford University Press.

Williams, K. (2020), 'Playing the Fields: Theorizing Research Impact and Its Assessment', Research Evaluation, 29 (2), 191-202.

Young, M., Sørensen, M. P., Bloch, C., and Degn, L. (2017), 'Systemic Rejection: Political Pressures Seen from the Science System', Higher Education, 74 (3), 491-505. 